\title{
Retrospective Evaluation of Return Visits to the Paediatric Emergency Department
}

\author{
(D) Esra Türe, (1) Abdullah Yazar
}

Department of Paediatric Emergency, Meram Medical Faculty, Necmettin Erbakan University, Konya, Turkey

\begin{abstract}
Aim: This study aimed to establish regional data using the results obtained via determination of clinical and demographic characteristics of patients who revisited the paediatric emergency department of a university hospital within 5 days.

Materials and Methods: Patients who revisited the paediatric emergency department within the first 5 days were included. Patient age and sex, complaints at admission, admission sessions and timeframes and whether the patients were admitted during or outside of working hours were recorded.

Results: The emergency department was revisited by 654 (1.32\%) patients. When patient distribution by age group was examined, 415 patients were found to be aged $<5$ years. When patient distribution based on working hours was examined, 302 patients were found to be admitted outside of working hours and on holidays, whereas 291 patients were usually admitted during the evenings.

Conclusion: Clinicians informing parents at the first visit of the details about their child's disease, the disease course and when to revisit the hospital after discharge may be an effective way to not only prevent unnecessary return visits but also alleviate the anxiety of parents and reduce medical errors and negative patient outcomes.
\end{abstract}

Keywords: Return visit, emergency department, children

\section{Introduction}

Determination of need for treatment and follow-up of the patient is one of the fundamental duties of the emergency department (ED) (1). Return visits (RV) of the patients whose treatments are organized in an inpatient or outpatient setting in ED and who are then discharged reflect natural history of the current disease or the quality of the care received at the initial visit (2). During holiday periods during which outpatient clinics are not provided, RV to ED is inevitable when a disease is progressed or a parent is anxious. In addition, reason of some of RVs may be due to systemic problems such as diagnostic errors, lack of an appropriate treatment at initial visit, insufficient education at discharge or limited access to a primary care provider (3).

$\mathrm{RV}$ rate has been used as a quality improvement measure for ED care and accepted as an indicator of health care quality or access to health care services (4). Researchers have been reported that more number of studies are needed in order to better understand frequent visits to ED, help identification populations at risk and develop interventions to reduce recurrent visits to ED (5). RVs have been accepted as high-risk cases with a potential of medical error and used as a quality improvement tool to identify preventable medical errors, and etiologies and tendencies of preventable RVs have been studied for modification of medical practices and improvement of quality (6). Studies conducted in United States have reported RV ratios of $2.5 \%$ to $3.5 \%$ among all ED visits (7, 8). There are no large studies on this issue conducted with a childhood group. Thus, in our study, formation of our regional data with the results obtained through determination of clinical and demographical characteristics of the patients who revisited the pediatric EDof a university hospital within five days is aimed.

\section{Materials and Methods}

After an ethics committee approval was obtained, the records on the automatic control system and the hospitalization files of the

Cite this article as: Türe E, Yazar A. Retrospective Evaluation of Return Visits to the Paediatric Emergency Department. Eurasian J Emerg Med. 2020;19(2):115-20 
patients under age of 18 who admitted to Necmettin Erbakan University Meram Medical Faculty Paediatric ED between January 2017 and January 2018 were examined (approval number: 2018/1166). Of the patients who were discharged after being followed-up in ED observation unit or issuance of a prescription; those who revisit to the pediatric ED within first five days were included in the study. Patients who did not visit again or who did visit after $>5$ days were excluded from the study (Figure 1: Flow Chart). Patients' age, gender, admission complaints, admission seasons, admission timeframe (morning, afternoon, evening, night), whether they admitted within or out of working hours, whether he/she followed the recommendations made at discharge and after how many days they admitted were recorded. Our study complies with World Medical Association Declaration of Helsinki "Ethical Principles for Medical Research Involving Human Subjects" principles.

\section{Statistical Analysis}

Statistical analysis of the study was performed by using the Statistical Package for the Social Sciences for Windows ver. 20.0 package program. Continuous variables were expressed as "mean \pm standard deviation". Categorical variables expressed as numerically was given as (\%). Descriptive statistics were used for distribution of the data and frequency analysis and chi-square tests were used for comparison of independent two groups for frequency data. Level of significance was considered to be $<0.05$ in all statistical analyses.

\section{Results}

It was determined that, of 49334 patients who admitted to Necmettin Erbakan University Meram Medical Faculty Paediatric ED between January 2017 and January 2018; 654 (1.32\%) revisited ED within first five days after they were discharged from the ED

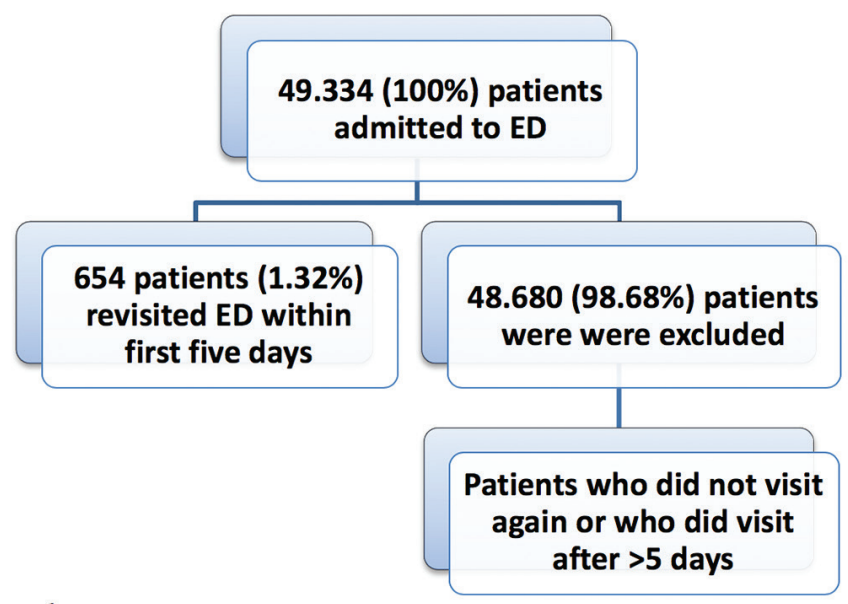

Figure 1. Flow chart

ED: Emergency department with their work-ups, examination and prescription procedures completed. Of these patients; 303 (46.3\%) were female and 351 (53.7\%) were male, and their mean age was $5.84 \pm 4.71$ years. When distribution of the patients by age groups was examined, it was observed that 415 (63.5\%) were under five years of age, 115 (17.6\%) were $5-10$ years old, 54 (8.3\%) were $11-15$ years old and 70 were over 15 years old. When complaints at RV were examined, it was determined that the patients revisited most commonly with a complaint of fever in 237 patients (36.2\%) and that it was followed by diarrhea $(n=98,15 \%)$ and poor feeding $(n=95,14.5 \%)$ (Figure 2). When the patients were examined by their diagnoses; it was observed that upper respiratory tract infections were most commonly diagnosed with being in 235 (36.1\%) patients and that it was followed by acute gastroenteritis $(n=180,27.5 \%)$ and exanthematous diseases $(n=56,8.6 \%)$ (Figure 3).

When distribution RV of the patients by seasons was examined it was determined that 223 (34.1\%) of the patients admitted most commonly during fall and followed by $27.7 \%$ in summer, $20.3 \%$ in spring and $17.9 \%$ in winter. When examined by timeframe, it was observed that 291 (44.5\%) patients were admitted most commonly at evening time. When distribution of RV by working hours was examined, it was determined that 302 (61.\%) patients

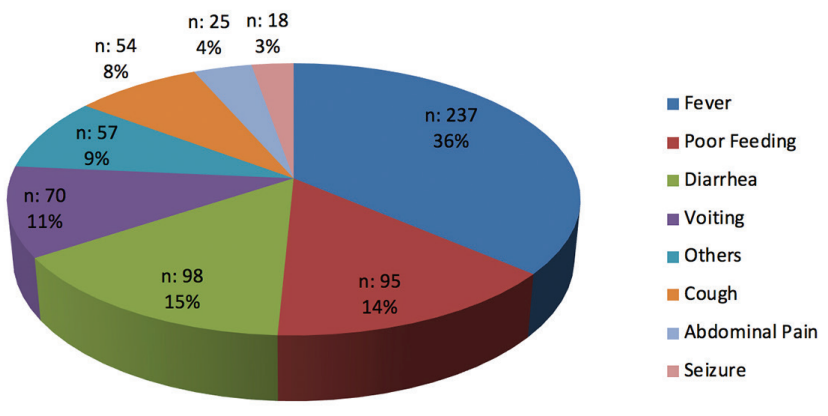

Figure 2. Distribution of the patients by revisit complaints $\mathrm{n}$ : Number

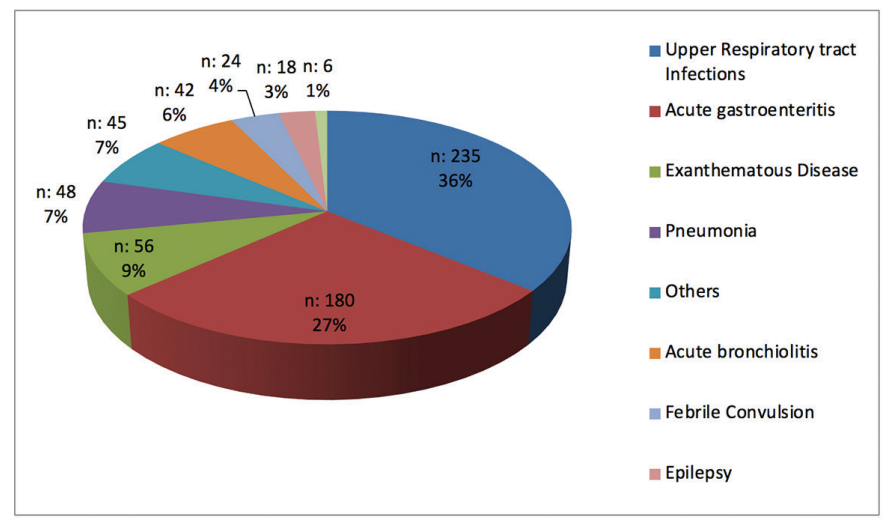

Figure 3. Distribution of the patients by diagnosis n: Number 
admitted out of working hours and during holidays. Figure 4 demonstrates that distribution of the patients by time to RV. of the patients; 528 (80.7\%) were determined not to follow the recommendations made at discharge or not to use the prescribed medications regularly.

It was determined that, of 654 patients revisited the paediatric ED; 504 (77.1\%) were discharged just after examination, 140 (21.4\%) were treated in inpatient setting, two $(0.3 \%)$ were referred, one (0.2\%) died, two (0.3\%) took "French leave" and five (0.8\%) left the hospital through signing a manuscript for refusal of treatment.

When the patients were compared by gender and age groups, it was determined that, of $115(17.6 \%)$ patients in 5-10 years of age group; 76 (66.1\%) were statistically significantly male $(p=0.001)$. When distribution of the diagnoses established and admission complaints by gender was examined, 16 (88.9\%) of 18 (2.8\%) diagnosed with epilepsy and 16 (88.9\%) of 18 (2.8\%) patients admitted with a complaint of having a seizure were determined to be statistically significantly male $(p=0.03$,

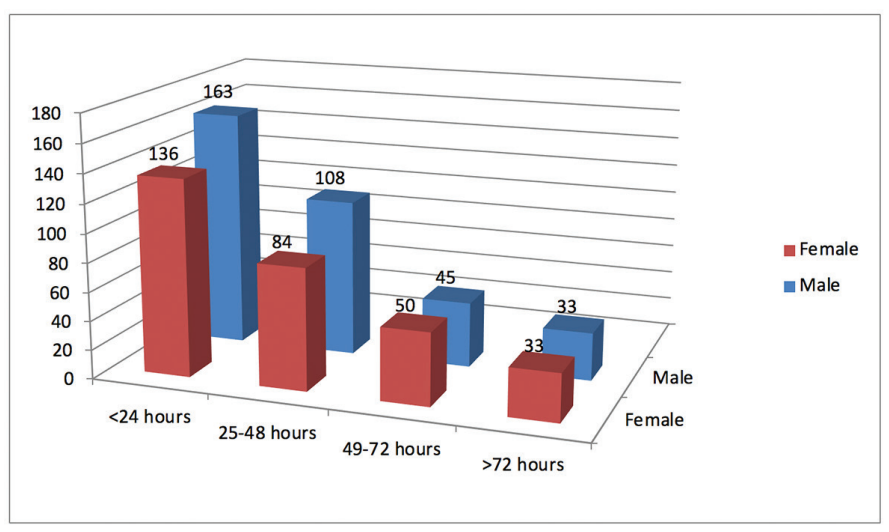

Figure 4. Distribution of the patients by time to revisit $p=0.01)$. When the age groups and admission timeframes were compared, 140 (70.7\%) of 198 (30.3\%) patients admitted in the afternoon were determined to be statistically significantly under five years of age $(p=0,001)$ (Table 1$)$. When the age groups and admission seasons were compared, 122 (67.4\%) of 181 (27.7\%) of the patients admitted during summer season were determined to be statistically significantly within the age group under five years of age $(p=0,01)$ (Table 1$)$. When the distribution of revisits by working hours and the age groups were compared, 178 (70.6\%) of 252 (38.5\%) patients admitted within working hours were determined to be statistically significantly within the age group under five years of age $(p=0.01)$ (Table 1$)$. Distribution of diagnoses of the patients by working hours is provided in Table 2 , distribution of the diagnoses by time to revisit is provided in Table 3.

\section{Discussion}

Primary duty of EDs is treatment of patients whose conditions are likely to worsen if immediately intervened. Patients who admit to ED also expect high-quality service, just like other patients. However, RV of patients to ED who can be managed in outpatient clinics will make ED, where is already an intensive working environment, more crowded and, thusly, will increase work load, lengthen patients' waiting time, lower quality of follow-up and treatment and lead to increased health care costs $(1,9,10)$. As a paediatric ED that provides a tertiary health care, our RV rates in our study were determined to be lower compared to the international literature. We are in thought of that this result arose from differences in international health care systems and differences in defining RV (intervals of 48 hours to 1 month after initial visit).

Table 1. Distribution of age groups of the patients by admission timeframes, admission seasons and working hours

\begin{tabular}{|c|c|c|c|c|c|}
\hline Age (year) & $<5$ & $5-10$ & $11-15$ & $>15$ & $\mathrm{p}$ \\
\hline \multicolumn{6}{|l|}{ Admission time frames } \\
\hline Morning & $76(60.3 \%)$ & $27(21.4 \%)$ & $14(11.1 \%)$ & $9(7.1 \%)$ & \multirow{4}{*}{0.001} \\
\hline Afternoon & $140(70.7 \%)$ & $24(12.1 \%)$ & $12(6.1 \%)$ & $22(11.1 \%)$ & \\
\hline Evening & $181(62.2 \%)$ & $60(20.6 \%)$ & $19(6.5 \%)$ & $31(10.7 \%)$ & \\
\hline Night & $18(46.2 \%)$ & $4(10.3 \%)$ & $9(23.1 \%)$ & $8(20.5 \%)$ & \\
\hline \multicolumn{6}{|l|}{ Season } \\
\hline Fall & $143(64.1 \%)$ & $46(20.6 \%)$ & $12(5.4 \%)$ & $22(9.9 \%)$ & \multirow{4}{*}{0.01} \\
\hline Winter & $72(61.5 \%)$ & $19(16.2 \%)$ & $8(6.8 \%)$ & $18(15.4 \%)$ & \\
\hline Spring & $78(58.6 \%)$ & $22(16.5 \%)$ & $22(16.5 \%)$ & $11(8.3 \%)$ & \\
\hline Summer & $122(67.4 \%)$ & $28(15.5 \%)$ & $12(6.6 \%)$ & $19(10.5 \%)$ & \\
\hline \multicolumn{6}{|l|}{ Working hours } \\
\hline Admitted within working hours & $178(70.6 \%)$ & $40(15.9 \%)$ & $17(6.7 \%)$ & $17(6.7 \%)$ & \multirow[b]{2}{*}{0.01} \\
\hline Admitted out of working hours & 237 (59\%) & $75(18.7 \%)$ & $37(9.2 \%)$ & $53(13.2 \%)$ & \\
\hline
\end{tabular}


Studies conducted in United States have reported RV ratios of $2.5 \%$ to $3.5 \%$ among all ED visits $(7,8)$. Many institutions and hospitals have been using RV rate as a comparison tool for quality of service provided. While many previous studies evaluated RVs thorough focusing on determination of problems in medical care provided during first visit (11), other group studies, however, analyzed RVs in regard to patient demographics and revealed many redundant RVs (12). In the survey study conducted by Augustine et al. (13) with parents of the cases, most common cause of RVs was determined to be persistence or worsening of pre-existing complaints. It was observed that there were also reasons including that parents did not know how to help their child, that they could not comprehend the disease and that they did not await persistence of the complaints. In our study, it was determined that $1.32 \%$ of the patients examined in paediatric ED revisited the ED within first five years during a one-year period RV rates have been using as a comparison tool for quality of service provided. Conduction of large, regional and national studies examining main causes of RVs will provide reduction of medical errors in EDs.
In the study of Alessandrini et al. (11), it was determined that RVs of the patients under two years of age were more and it was considered that this could be related to increased anxiety of parents about the disease. Similarly, in the study of Goldman et al. (1), RV rate was determined to be higher among preschoolaged children ( $<6$ years of age) compared to older children and it was concluded that the younger a child is, the higher RV rate observed. Similarly, in our study, 63.5\% of the patients were determined to be under five years of age. These findings suggest that they might be due to underdeveloped communicative skills of younger children, their inability to express discomfort and distress and less experienced parents of a younger child, as well as the fact that physicians are more sensitive to worsening of symptoms in younger children, that they give advice for this issue and that they arrange a control visit for these patients more frequently.

In the study of Alessandrini et al. (11), the most common pediatric diagnosis in RVs was determined to be infectious diseases and it was concluded that RVs were more commonly observed during winter season and that could be associated

Table 2. Distribution of diagnoses of the patients by working hours

\begin{tabular}{|l|l|l|l|l|}
\hline & \multicolumn{2}{l|}{ Those admitted within working hours } & \multicolumn{2}{l|}{ Those admitted out of working hours } \\
\cline { 2 - 5 } & $\mathbf{n}$ & $\%$ & $\mathbf{n}$ & \% \\
\hline Upper respiratory tract infections & 96 & 40.9 & 139 & 59.1 \\
\hline Acute bronchiolitis & 15 & 35.7 & 27 & 64.3 \\
\hline Pneumonia & 16 & 33.3 & 32 & 66.7 \\
\hline Acute gastroenteritis & 76 & 42.2 & 104 & 57.8 \\
\hline Epilepsy & 8 & 44.4 & 10 & 55.6 \\
\hline Febrile convulsion & 10 & 41.7 & 6 & 58.3 \\
\hline Urinary tract infections & 0 & 0 & 42 & 100 \\
\hline Exanthematous diseases & 14 & 25 & 28 & 75 \\
\hline Others & 17 & 37.8 & & 62.2 \\
\hline n: Number & & & \\
\hline
\end{tabular}

Table 3. Distribution of diagnoses of the patients by time to revisit

\begin{tabular}{|c|c|c|c|c|c|c|c|c|}
\hline & \multicolumn{2}{|c|}{$<24$ hours } & \multicolumn{2}{|c|}{ 25-48 hours } & \multicolumn{2}{|c|}{ 49-72 hours } & \multicolumn{2}{|c|}{$>72$ hours } \\
\hline & $\mathbf{n}$ & $\%$ & $\mathrm{n}$ & $\%$ & $\mathbf{n}$ & $\%$ & $\mathbf{n}$ & $\%$ \\
\hline Upper respiratory tract infections & 114 & 48.5 & 66 & 28.1 & 30 & 12.8 & 25 & 10.6 \\
\hline Acute bronchiolitis & 18 & 42.9 & 12 & 28.6 & 8 & 19 & 4 & 9.5 \\
\hline Pneumonia & 16 & 33.3 & 16 & 33.3 & 8 & 16.7 & 8 & 16.7 \\
\hline Acute gastroenteritis & 83 & 46.1 & 51 & 28.3 & 28 & 15.6 & 18 & 10 \\
\hline Epilepsy & 11 & 61.1 & 6 & 33.3 & 0 & 0 & 1 & 5.6 \\
\hline Febrile convulsion & 12 & 50 & 6 & 25 & 6 & 25 & 0 & 0 \\
\hline Urinary tract infections & 2 & 33.3 & 1 & 16.7 & 1 & 16.7 & 2 & 33.3 \\
\hline Exanthematous diseases & 26 & 46.4 & 17 & 30.4 & 9 & 16.1 & 4 & 7.1 \\
\hline Others & 17 & 37.8 & 17 & 37.8 & 5 & 11.1 & 6 & 13.3 \\
\hline
\end{tabular}


with infectious diseases. Similarly, also in the study of Cho et al. (14), RVs within first 72 hours were determined to be due to infectious diseases at a rate of $29.9 \%$. In the study of de VosKerkhof et al. (15) symptoms such as fever, shortness of breath and vomiting/diarrhea were determined to be associated with emergency medical care RVs in children. In consistency with the literature, the most common RV admission complaint in our study was fever, whereas the most common revisit diagnosis was upper respiratory tract infections. When the distribution of RVs by seasons was examined, it was determined that RVs were most common during fall. It was considered that this might be due to continental climate of our region and increased rate of infections with cooling of the climate during fall.

In the study of Saunders et al. (16), majority of RVs were determined to take place during evening and night shifts. Similarly, in the study of Alessandrini et al. (11), it was determined that of the RVs; $40 \%$ took place during day shift, $47 \%$ during evening shift and $13 \%$ during night shift and that this reflected general ED population. Similarly to the literature, it was determined that $44.5 \%$ of RVs took place most commonly during evening time and $61.5 \%$ of the patients admitted out of working hours and during holidays. It was considered that this might be due to preference of admission out of working hours because of working conditions, faster care providing in ED and difficulty in accessing outpatient care services.

In the study of Akenroye et al. (17), it was determined that of the RVs; more than $80 \%$ were re-discharged and only $19.7 \%$ were hospitalized. Similarly, also in our study, it was determined that of the RVs; $77.1 \%$ were discharged after being examined and 21.4\% were hospitalized. In our study, one patient was found to be brought to the hospital as exitus. This patient was patient who was under one year of age, diagnosed with acute gastroenteritis and could not be fed at home after being discharged and already died when brought to the hospital after recognition by the parents. It was observed in our study that vast majority of RVs were re-discharged and this, in turn, suggests that significant number of patients use EDs for non-emergency medical conditions. However, our patient who died indicates how fast symptoms can progress especially in younger patients. Therefore, sufficient informing of and giving advice to parents at initial visits are essential. Furthermore, it is necessary for clinicians not to consider RVs as patients who misuse or abuse EDand to take detailed history and to perform physical examinations in an extrajudicial manner.

\section{Conclusion}

RV rate was determined to be $1.32 \%$ in our study. It was observed that, of these; $77.1 \%$ were discharged just after RV, $63.5 \%$ were under five years of age, that the patients admitted most commonly due to an infectious disease, that vast majority of the patients admitted out of working hours and most commonly during fall. When ED clinicians inform the parents in details during first visit about their child's disease, course of the disease and when to revisit a hospital after discharge may be an effective way not only for prevention of redundant RVs, but also for prevention anxiety of the parents, as well as for reduction of medical errors and negative patient outcomes. Additionally, conduction of large, regional and national studies examining main causes of RVs together with clinical and demographical characteristics will provide reduction of medical errors in EDs, improvement of quality of health care provided and reduction of the financial load.

\section{Ethics}

Ethics Committee Approval: Ethical approval was obtained from Necmettin Erbakan University Meram Medical Faculty Paediatric Emergency Department (approval number, 2018/1166).

Informed Consent: Retrospective study.

Peer-review: Externally peer-reviewed.

\section{Authorship Contributions}

Surgical and Medical Practices: E.T., A.Y., Concept: E.T., A.Y., Design: E.T., A.Y., Data Collection or Processing: E.T., A.Y., Analysis or Interpretation: E.T., A.Y., Literature Search: E.T., A.Y., Writing: E.T., A.Y.

Conflict of Interest: No conflict of interest was declared by the authors.

Financial Disclosure: The authors declared that this study received no financial support.

\section{References}

1. Goldman RD, Ong M, Macpherson A. Unscheduled return visits to the pediatric emergency department-one-year experience. Pediatr Emerg Care. 2006;22:545-9.

2. Rising KL, White LF, Fernandez WG, Boutwell AE. Emergency department visits after hospital discharge: a missing part of the equation. Ann Emerg Med. 2013; 62:145-50.

3. Pediatrics AAo, Medicine CoPE, Physicians ACoE, Committee P, Association EN. Joint policy statement-guidelines for care of children in the emergency department. J Emerg Nurs. 2013;39:116-31.

4. Depiero AD, Ochsenschlager DW, Chamberlain JM. Analysis of pediatric hospitalizations after emergency department release as a quality improvement tool. Ann Emerg Med. 2002;39:159-63.

5. Pines JM, Asplin BR, Kaji AH, Lowe RA, Magid DJ, Raven M, et al. Frequent users of emergency department services: gaps in knowledge and a proposed research agenda. Acad Emerg Med. 2011;18:e64-e9.

6. Pierce JM, Kellerman AL, Oster C. "Bounces": an analysis of short term return visits to a public hospital emergency department. Ann Emerg Med. 1990;19:752-7. 
7. Gordon JA, An LC, Hayward RA, Williams BC. Initial emergency department diagnosis and return visits: risk versus perception. Ann Emerg Med. 1998;32:569-73.

8. Zimmerman DR, McCarten-Gibbs KA, DeNoble DH, Borger C, Fleming J, Hsieh $M$ et al. Repeat pediatric visits to a general emergency department. Ann Emerg Med. 1996;28:467-73.

9. Vaduganathan M, Bonow RO, Gheorghiade M. Thirty-day readmissions: the clock is ticking. JAMA. 2013;309:345-6.

10. Stang AS, Straus SE, Crotts J, Johnson DW, Guttmann A. Quality indicators for high acuity pediatric conditions. Pediatrics. 2013;132:752-62.

11. Alessandrini EA, Lavelle JM, Grenfell SM, Jacobstein CR, Shaw KN. Return visits to a pediatric emergency department. Pediatr Emerg Care. 2004;20:166-71.

12. Gregor MA, Wheeler JR, Stanley RM, Mahajan PV, Maio RF, Piette JD. Great Lakes Emergency Medical Services for Children Research Network. Caregiver adherence to follow-up after an emergency department visit for common pediatric illnesses: Impact on future ED use. Med Care. 2009;47:326-33.
13. Augustine EM, Bekker TD, Goel A, Breslin KA, Chamberlain JM. A Survey of Return Visits to the Pediatric Emergency Department: The Caretakers' Perspective. Pediatr Emerg Care. 2018;34:27-32.

14. Cho CS, Shapiro DJ, Cabana MD, Maselli JH, Hersh AL. A national depiction of children with return visits to the emergency department within 72 hours, 2001-2007. Pediatr Emerg Care. 2012;28:606-10.

15. de Vos-Kerkhof E, Geurts DHF, Steyerberg EW, Lakhanpaul M, Moll HA, Oostenbrink R. Characteristics of revisits of children at risk for serious infections in pediatric emergency care. Eur J Pediatr. 2018;177:617-24

16. Saunders NR, To T, Parkin PC, Guttmann A. Emergency Department Revisits by Urban Immigrant Children in Canada: A Population-Based Cohort Study. J Pediatr. 2016;170:218-26.

17. Akenroye AT, Thurm CW, Neuman MI, Alpern ER, Srivastava G, Spencer SP, et al. Prevalence and predictors of return visits to pediatric emergency departments. J Hosp Med. 2014;9:779-87. 